\title{
In vitro anticancer effects of a RAGE inhibitor discovered using a structure-based drug design system
}

\author{
ALI HAFEZ ALI MOHAMMED EL-FAR ${ }^{1,2^{*}}$, SEIICHI MUNESUE ${ }^{1 *}$, AI HARASHIMA ${ }^{1}$, \\ AKIRA SATO $^{3}$, MIKA SHINDO $^{3}$, SHINGO NAKAJIMA $^{3}$, MANA INADA $^{3}$, MARIKO TANAKA $^{1}$, \\ AKIHIKO TAKEUCHI ${ }^{4}$, HIROYUKI TSUCHIYA ${ }^{4}$, HIROSHI YAMAMOTO ${ }^{1}$, HAZEM M.E. SHAHEEN ${ }^{5}$, \\ YASSER S. EL-SAYED ${ }^{6}$, SHUHEI KAWANO ${ }^{1}$, SEI-ICHI TANUMA ${ }^{3}$ and YASUHIKO YAMAMOTO ${ }^{1}$
}

\begin{abstract}
${ }^{1}$ Department of Biochemistry and Molecular Vascular Biology, Kanazawa University Graduate School of Medical Sciences, Kanazawa, Ishikawa 920-8640, Japan; ${ }^{2}$ Department of Biochemistry, Faculty of Veterinary Medicine, Damanhour University, Damanhour 22511, Egypt; ${ }^{3}$ Department of Biochemistry, Faculty of Pharmaceutical Sciences, Tokyo University of Science, Chiba 278-8510; ${ }^{4}$ Department of Orthopedic Surgery, Kanazawa University Graduate School of Medical Sciences, Kanazawa, Ishikawa 920-8641, Japan; Departments of ${ }^{5}$ Pharmacology and ${ }^{6}$ Veterinary Forensic Medicine and Toxicology, Faculty of Veterinary Medicine, Damanhour University, Damanhour 22511, Egypt
\end{abstract}

Received June 8, 2017; Accepted November 29, 2017

DOI: $10.3892 / 01.2018 .7902$

\begin{abstract}
Receptor for advanced glycation end-products (RAGE) is a pattern recognition receptor implicated in the pathogenesis of certain types of cancer. In the present study, papaverine was identified as a RAGE inhibitor using the conversion to small molecules through optimized-peptide strategy drug design system. Papaverine significantly inhibited RAGE-dependent nuclear factor $\mathrm{k}$-B activation driven by high mobility group box-1, a RAGE ligand. Using RAGE- or dominant-negative RAGE-expressing HT1080 human fibrosarcoma cells, the present study revealed that papaverine suppressed RAGE-dependent cell proliferation and migration dose-dependently. Furthermore, papaverine significantly inhibited cell invasion. The results of the present study
\end{abstract}

Correspondence to: Professor Yasuhiko Yamamoto, Department of Biochemistry and Molecular Vascular Biology, Kanazawa University Graduate School of Medical Sciences, 13-1 Takara-machi, Kanazawa, Ishikawa 920-8640, Japan

E-mail: yasuyama@med.kanazawa-u.ac.jp

${ }^{*}$ Contributed equally

Abbreviations: RAGE, receptor for advanced glycation end-products; COSMOS, conversion to small molecules through optimized-peptide strategy; NF- $\mathrm{B}$, nuclear factor $\kappa \mathrm{B}$; AGE, advanced glycation end-products; $\mathrm{A} \beta$, amyloid- $\beta$; HMGB, high-mobility group box; Rac1, RAS-related C3 botulinum toxin substrate 1; Cdc42, cell division control protein 42 homolog; SBVS, structure-based virtual screening; ERK, extracellular signal-regulated kinase

Key words: receptor for advanced glycation end-products, cancer malignancy, papaverine, fibrosarcoma cells suggested that papaverine could inhibit RAGE, and provided novel insights into the field of RAGE biology, particularly anticancer therapies.

\section{Introduction}

Receptor for advanced glycation end products (RAGE) is a pattern recognition receptor that binds multiple ligands, including AGE (1), S100 proteins (2), lipopolysaccharides (3), phosphatidylserine (4), amyloid- $\beta$ (A $\beta$ ) (5), and high mobility group box (HMGB)-1 (6). Interactions of these diverse ligands with RAGE result in intracellular signaling, including nuclear factor $\kappa-\mathrm{B}(\mathrm{NF}-\mathrm{\kappa B})$ activation, which results in pathogenic processes such as diabetic complications (7), inflammatory diseases, Alzheimer's disease (AD) (8) and cancer (9). Takeuchi et al (10) demonstrated that RAGE expression in HT1080 human fibrosarcoma cells induced tumor cells to proliferate, migrate, invade and metastasize. HMGB-1 was revealed to induce RAS-related $\mathrm{C} 3$ botulinum toxin substrate (Rac)1 and cell division control protein 42 homolog (Cdc42) functions in RAGE-expressing HT1080 fibrosarcoma cells (10). Epidemiological studies also demonstrated that RAGE expression was associated with tumor malignancies of the stomach (11), colon and rectum (12-14), prostate (15), breast (16) and bone (17). Therefore, these previous studies suggested that RAGE represents a potential therapeutic target, and that inhibiting RAGE may be useful to anticancer strategies.

Previously, Sakai et al (18) developed a novel drug design system, involving the conversion of optimized binding peptide to non-peptidic small molecules by structure-based virtual screening (SBVS), followed by optimization of the small molecules using a structure-based drug design system, namely conversion to small molecules through optimized-peptide strategy (COSMOS). Using this strategy, the most optimized binding peptide is first computationally designed on a hot spot 
in the target protein. Subsequently, the optimized binding peptide may be converted to small molecules by SBVS based on its pharmacophore. Then, the selected candidates are evaluated using in vitro assays. Therefore, this strategy decreases the cost and time required to search for effective lead compounds, for drug design and for optimization (18). The present study identified a RAGE inhibitor, papaverine, using this drug design system. Papaverine is an opiate alkaloid, originally isolated from the plant Papaver somniferum and now synthetically produced as a direct-acting smooth muscle relaxant. Its mechanism of action may be associated with non-selective inhibition of phosphodiesterases and direct inhibition of calcium channels $(19,20)$.

The present study assessed whether papaverine functioned as a RAGE inhibitor using in vitro cell culture systems of RAGE- and dominant-negative (dn)RAGE-expressing HT1080 fibrosarcoma cells.

\section{Materials and methods}

Papaverine. Papaverine hydrochloride (molecular weight, 375.85 Da; product number, P0016) was purchased from Tokyo Chemical Industry Co., Ltd. (Tokyo, Japan).

Cell lines. HT1080 human fibrosarcoma cells (American Type Culture Collection, Manassas, VA, USA) were transfected with a plasmid containing human full-length RAGE cDNA or cytoplasmic domain-deleted dnRAGE cDNA, or with the vector alone, as previously described $(21,22)$. The cells were designated as RAGE-expressing, dnRAGE-expressing or mock-transfected (mock) HT1080 cells, respectively. Cells were maintained in RPMI-1640 medium (Nakarai Tesque, Kyoto, Japan) supplemented with $10 \%$ fetal bovine serum (FBS; Nichirei Biosciences Inc., Tokyo, Japan), 100 U/ml penicillin and $100 \mu \mathrm{g} / \mathrm{ml}$ streptomycin in the presence of G418 (geneticin, $200 \mu \mathrm{g} / \mathrm{ml}$; Roche Applied Science, Mannheim, Germany).

$N F-\kappa B$ luciferase assay. Stably transfected rat C6 glioma cells that expressed human RAGEand the $\mathrm{NF}-\kappa \mathrm{B}$ enhancer-luciferase system (pNF-кB-Luc; Agilent Technologies, Inc., Santa Clara, CA, USA) were used in this assay, as previously described (21). After a $4 \mathrm{~h}$ incubation at $37^{\circ} \mathrm{C}$ in a humidified $5 \% \mathrm{CO}_{2}$ atmosphere in Dulbecco's modified Eagle's medium supplemented with $0.1 \%$ FBS, the cells were stimulated with $1 \mu \mathrm{g} / \mathrm{ml}$ HMGB-1 (Sigma-Aldrich; Merck KGaA, Darmstadt, Germany) or with $100 \mu \mathrm{g} / \mathrm{ml}$ glyceraldehyde-derived AGE-modified bovine serum albumin (BSA) (Sigma-Aldrich; Merck KGaA) (21) with/without 10 or $20 \mu \mathrm{M}$ papaverine or $0.08 \%$ dimethy sulfoxide (DMSO) as a negative control for $4 \mathrm{~h}$ at $37^{\circ} \mathrm{C}$ in a humidified $5 \% \mathrm{CO}_{2}$ atmosphere. Luciferase activity was determined using the luciferase assay system (Promega Corporation, Madison, WI, USA) and an LB 941 Multimode Reader TriStar (Berthold Technologies GmbH \& Co. KG, Bad Wildbad, Germany). These experiments were repeated three times.

Western blot analysis. RAGE- and dnRAGE-expressing HT1080 cells and mock control cells which were incubated with 0,10 and $20 \mu \mathrm{M}$ papaverine for $72 \mathrm{~h}$ at $37^{\circ} \mathrm{C}$ in a humidified $5 \% \mathrm{CO}_{2}$ atmosphere, were washed with ice cold PBS, scraped off in PBS and pelleted by centrifugation at $300 \mathrm{x}$ g for $5 \mathrm{~min}$ at $4^{\circ} \mathrm{C}$. The cells were lysed immediately by sonication in 1\% Triton X-100 (Sigma-Aldrich; Merck KGaA), $50 \mathrm{mM}$ Tris- $\mathrm{HCl}, \mathrm{pH} 7.5,150 \mathrm{mM} \mathrm{NaCl}$ and protease inhibitor cocktail (Sigma-Aldrich; Merck KGaA, Darmstadt, Germany), and then centrifuged at $10,000 \mathrm{x}$ g for $10 \mathrm{~min}$ at $4^{\circ} \mathrm{C}$. The cell lysates (50 $\mu \mathrm{g}$ of protein) were separated via $12.5 \%$ SDS-PAGE and electroblotted onto polyvinylidene fluoride membranes (EMD Millipore, Billerica, MA, USA). The membranes were blocked at room temperature for $1 \mathrm{~h}$ with $5 \%(\mathrm{w} / \mathrm{v})$ non-fat dried milk in PBS, and then incubated at room temperature for $1 \mathrm{~h}$ with either a rabbit anti-human RAGE-specific polyclonal antibody $(1: 1,000)$ produced as described previously (21) or a mouse anti $\beta$-actin antibody (cat. no. A5441, 1:10,000; Sigma-Aldrich; Merck KGaA). Goat anti-rabbit IRDye 680 (cat. no. P/N 926-32221) and goat anti-mouse IRDye $800 \mathrm{CW}$ (P/N 925-32210) were diluted 10,000-fold and used as the secondary antibodies. The antigen-antibody complex was visualized using the Odyssey Infrared Imaging System version 3.0 (LI-COR Biosciences, Lincoln, NE, USA). These experiments were repeated two times. Secondary antibody only was used as a negative control.

Plate-binding assays. Competitive binding inhibition assay with papaverine was performed using a 96-well AGE-BSA-coated plate as previously described (21). Briefly, $50 \mathrm{ng} / \mathrm{ml}$ soluble RAGE (sRAGE) was incubated with or without 10 or $20 \mu \mathrm{M}$ of papaverine or $0.08 \%$ DMSO as a negative control on an AGE-BSA-coated plate at room temperature for $1 \mathrm{~h}$. Following incubation and washed three times with $0.01 \%$ Tween-20, 0.15 M NaCl, $20 \mathrm{mM}$ Tris- $\mathrm{HCl}(\mathrm{pH} 7.5)$, horseradish peroxidase (HRP)-labeled anti-RAGE antibody (in human esRAGE ELISA kit; ready-to-use; cat. no. K1009-1; B-Bridge International, Inc., Santa Clara, CA, USA) was added and the plate was further incubated at room temperature for $1 \mathrm{~h}$. The HRP-labeled antibody-sRAGE-AGE complex was then detected by measuring the absorbance at $450 \mathrm{~nm}$ using the microplate reader iMark (Bio-Rad Laboratories, Inc., Hercules, CA, USA). These experiments were repeated three times.

Cell proliferation assay. RAGE- and dnRAGE-expressing HT1080 cells and mock control cells were inoculated $\left(1 \times 10^{3}\right.$ cells/well) at $37^{\circ} \mathrm{C}$ in a humidified $5 \% \mathrm{CO}_{2}$ atmosphere in a 96-well plate (BD Biosciences, Franklin Lakes, NJ, USA) containing RPMI-1640 medium supplemented with 10\% FBS and 0,10 or $20 \mu \mathrm{M}$ papaverine or $0.08 \%$ DMSO as a negative control. Following inoculation, the total viable cell number was counted using a hemocytometer using the dye exclusion method with $0.2 \%$ Trypan blue at room temperature (Thermo Fisher Scientific, Inc.) using an inverted light microscope (Primovert, Zeiss, Carl Zeiss Industrielle Messtechnik GmbH, Oberkochen, Germany) at magnification, $\mathrm{x} 4$ objective at 0,24 , 48 and $72 \mathrm{~h}$. These experiments were repeated three times.

Cell migration assay. Cell migration was evaluated using the monolayer denudation assay as previously described (10). Briefly, RAGE- and dnRAGE-expressing HT1080 and mock control cells were inoculated $\left(2 \times 10^{5}\right.$ cells/well) and were 
cultured to $100 \%$ confluence in a 12 -well plate. Cells were then wounded by denuding a strip of the monolayer (width, $\sim 1 \mathrm{~mm}$ ) with a $200 \mu \mathrm{l}$ pipette tip. Cells were washed twice with serum-free RPMI-1640 medium, and then incubated for $20 \mathrm{~h}$ at $37^{\circ} \mathrm{C}$ under a humidified $5 \% \mathrm{CO}_{2}$ atmosphere in RPMI-1640 containing $0.1 \%$ FBS with/without 10 or $20 \mu \mathrm{M}$ papaverine or $0.08 \%$ DMSO as negative control. The rate of wound closure was assessed in four separate fields of view $20 \mathrm{~h}$ after denudation using a light microscope (magnification, $\mathrm{x} 4$ objective). These experiments were repeated three times.

Cell invasion assay. A total of $\mathrm{mg} / \mathrm{ml}$ of matrigel-coated porous filters (pore size, $8 \mu \mathrm{m}$ ) in a 24-well format (BD Biosciences) were used as barriers in Boyden chambers to assess the extent of invasion by RAGE- and dnRAGE-expressing HT1080 cells and mock controls. Cells were plated $\left(2 \times 10^{5}\right.$ cells) in the upper chambers with RPMI-1640 containing 0.1\% BSA in the presence or absence of 10 or $20 \mu \mathrm{M}$ papaverine or $0.08 \%$ DMSO as negative control. The lower chambers were filled with $750 \mu \mathrm{l}$ RPMI-1640 containing 1\% FBS in the presence or absence of 10 or $20 \mu \mathrm{M}$ papaverine. Following a 20 -h incubation at $37^{\circ} \mathrm{C}$ in a humidified $5 \% \mathrm{CO}_{2}$ atmosphere, membranes were cut and removed from the insert housings. The filter membrane was fixed in $4 \%$ paraformaldehyde at room temperature for 2 min following the removal of non-invasive cells from the upper surface using a cotton swab. The bottom surface with the invasive cells was stained with $0.1 \%$ crystal violet at room temperature for $1 \mathrm{~min}$, and the invasive cells were counted in six fields of view using a light microscope (magnification, $\mathrm{x} 4$ objective) as previously described (10). These experiments were repeated three times.

Statistical analysis. Statistical analysis was performed using one-way analysis of variance with the Tukey-Kramer post-hoc test. These tests were conducted using Ekuseru-Toukei 2015 (Social Survey Research Information Co., Ltd., Tokyo, Japan). Data are presented as mean \pm standard error of the mean. $\mathrm{P}<0.05$ was considered to indicate a statistically significant difference.

\section{Results}

Inhibitory effects of papaverine on RAGE-dependent $N F-\kappa B$ activity. The present study assessed the inhibitory effects of papaverine on the RAGE-dependent NF- $\mathrm{KB}$ intracellular signaling pathway. Using the $\mathrm{C} 6$ glioma system, which reflected RAGE-dependent NF- $\kappa B$ activity (21), HMGB-1-induced activation of NF- $\kappa \mathrm{B}$ was evaluated in the presence or absence of papaverine in the culture media. Adding HMGB-1 significantly induced intracellular NF- $\mathrm{KB}$ activation $(\mathrm{P}<0.01)$; however, this upregulation was inhibited by papaverine treatment (10 or $20 \mu \mathrm{M}$; Fig. 1A). In addition, the increase in NF- $\kappa \mathrm{B}$ activity induced by glyceraldehyde-derived AGE-BSA, another RAGE ligand, was significantly inhibited by papaverine (Fig. 1B). The results of the present study suggested that papaverine could inhibit the RAGE-dependent intracellular signaling pathway. The present study subsequently confirmed the papaverine-RAGE binding using a plate assay (21). Papaverine significantly and dose-dependently competed for the binding between glyceraldehyde-derived AGE-BSA and recombinant
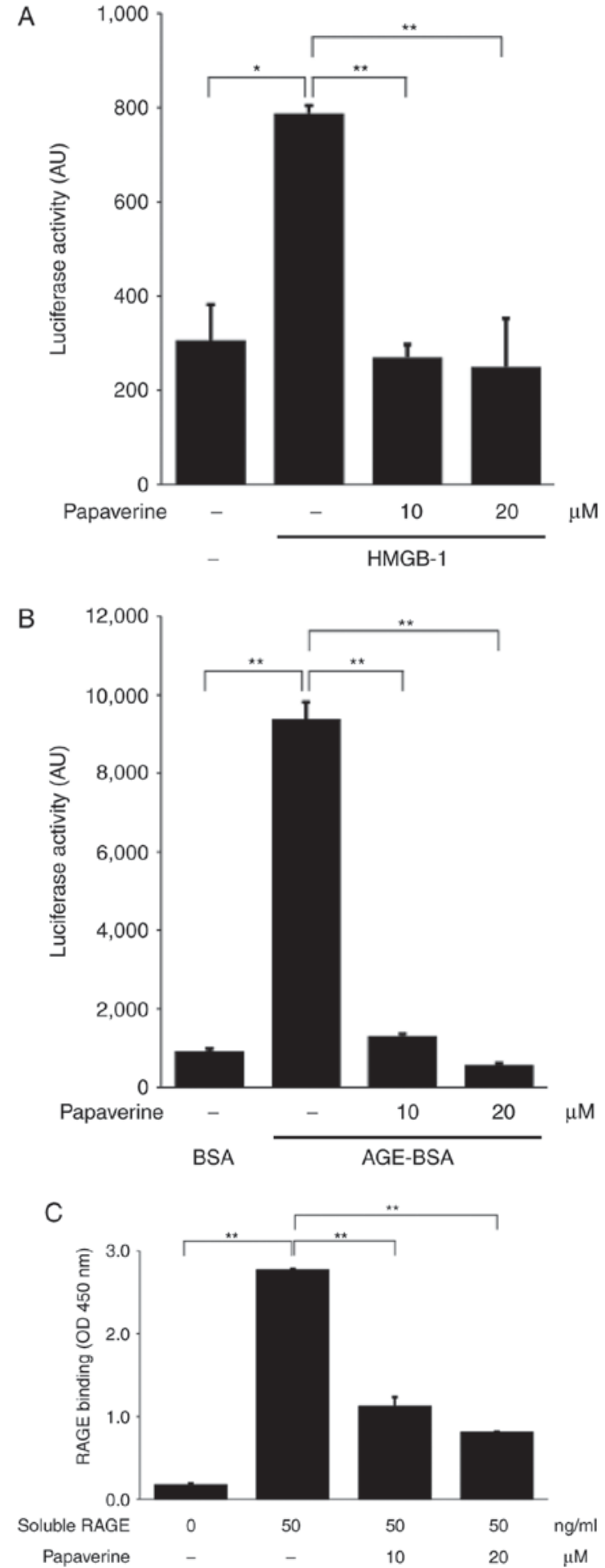

Figure 1. Papaverine inhibits HMGB-1 and AGE-BSA-induced RAGE signaling. Cells were stimulated with (A) $1 \mu \mathrm{g} / \mathrm{ml} \mathrm{HMGB}-1$ or (B) $100 \mu \mathrm{g} / \mathrm{ml}$ AGE-BSA with or without 10 or $20 \mu \mathrm{M}$ papaverine for $4 \mathrm{~h}$. The luciferase activity was measured and expressed as arbitrary units (AU). Values represent the mean \pm standard error of the mean $(\mathrm{n}=3)$. BSA, $100 \mu \mathrm{g} / \mathrm{ml}$ non-glycated BSA as a negative control; ${ }^{* *} \mathrm{P}<0.01$ vs. $1 \mu \mathrm{g} / \mathrm{ml} \mathrm{HMGB}-1 ;{ }^{*} \mathrm{P}<0.05$ vs. $1 \mu \mathrm{g} / \mathrm{ml}$ HMGB-1. (C) A plate binding assay. AGE-BSA-RAGE binding was competitively inhibited by papaverine. ${ }^{* *} \mathrm{P}<0.01 \mathrm{vs.} 50 \mathrm{ng} / \mathrm{ml}$ soluble RAGE. HMGB, high mobility group box; AGE, advanced glycation end-products; BSA, bovine serum albumin; RAGE, receptor for advanced glycation end-products; OD, optical density; soluble RAGE, recombinant soluble RAGE.

soluble RAGE (Fig. 1C), which suggested that the binding site of papaverine to RAGE may be shared with that of AGE-BSA. 
A

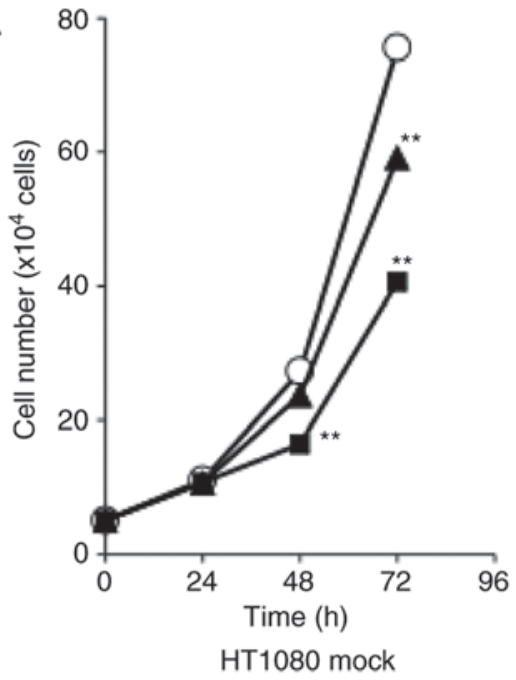

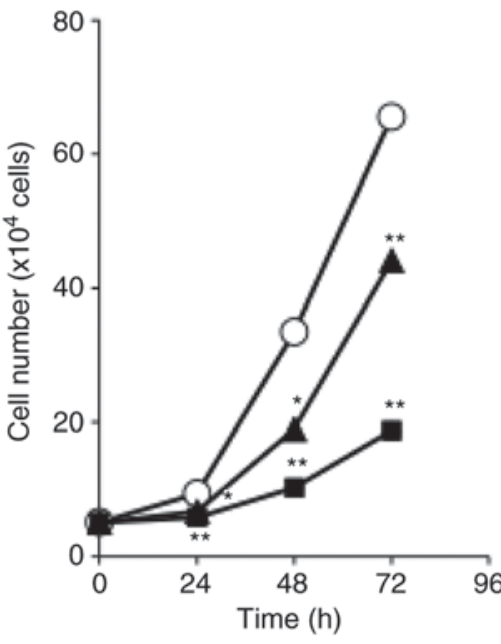

HT1080 full RAGE

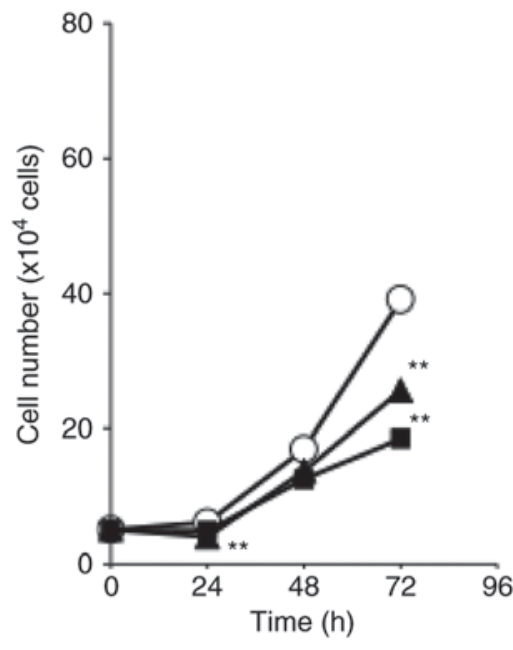

HT1080 dn RAGE

B

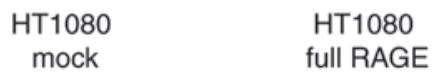

HT1080

dn RAGE

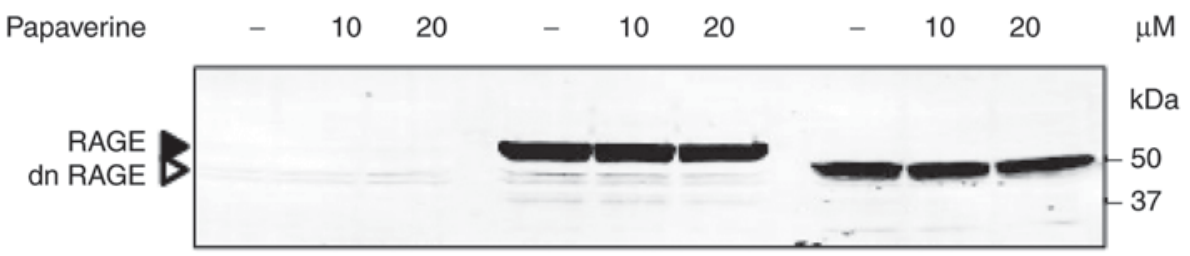

$\beta$-actin

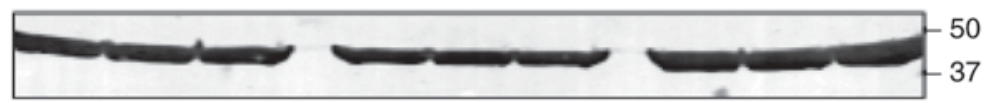

Figure 2. Papaverine decreases RAGE-induced cell proliferation in HT1080 fibrosarcoma cells. (A) Total viable cell number was determined at 0, 24, 48 and $72 \mathrm{~h}$ following inoculation of HT1080 RAGE, HT1080 dnRAGE and HT1080 mock cells in RPMI-1640 medium supplemented with 10\% fetal bovine serum with or without 10 or $20 \mu \mathrm{M}$ papaverine. Values represent the mean \pm standard error of the mean ( $\mathrm{n}=3$ ). Open circle, non-treated control; closed triangle, $10 \mu \mathrm{M}$ papaverine; closed square, $20 \mu \mathrm{M}$ papaverine. ${ }^{*} \mathrm{P}<0.05$ and ${ }^{* *} \mathrm{P}<0.01$ vs. non-treated control. (B) Western blotting. Human RAGE- and dnRAGE-expressing HT1080 and mock control cells were treated with or without papaverine for $72 \mathrm{~h}$. Closed and open arrow heads indicate RAGE and dnRAGE proteins, respectively. RAGE, receptor for advanced glycation end-products; dn, dominant-negative.

Inhibitory effects of papaverine on RAGE-dependent cell proliferation, migration and invasion. To mimic RAGE-dependent tumor malignant behaviors and assess the inhibitory effects of papaverine, the present study used an established human fibrosarcoma cell line HT1080 that expressed human RAGE and dnRAGE and the mock control cells. The HT1080 cells expressed HMGB1 and secreted HMGB1 levels did not differ among the mock-transfected, RAGE-expressing and dnRAGE-expressing HT1080 cells (10). The present study assessed the effects of papaverine treatment on HT1080 cell proliferation. Papaverine significantly and dose-dependently decreased the proliferation rate of RAGE-expressing HT1080 cells ( $\mathrm{P}<0.05$ vs. non-treated HT1080 cells; $P<0.01$ vs.non-treated HT1080 cells). In particular, at $20 \mu \mathrm{M}$ it was most effective between treated and non-treated conditions in RAGE-expressing HT1080 cells (65.5\% reduction) at $48 \mathrm{~h}$ (Fig. 2A). A reduction (39.8\%) was also observed between treated and non-treated conditions in the mock control cells at $48 \mathrm{~h}$; however, its effectiveness was decreased in dnRAGE-expressing HT1080 cells (26.2\% reduction) (Fig. 2A). Papaverine did not change the protein expression levels of RAGE and dnRAGE in the RAGE-expressing and dnRAGE-expressing HT1080 cells, respectively (Fig. 2B). Whether papaverine could inhibit the RAGE-dependent migration and invasion of HT1080 cells was also assessed in vitro. The inhibitory effects of papaverine on cell migration were observed between treated and non-treated RAGE-expressing HT1080 cells. Additionally, the inhibitory effects were observed between treated and non-treated conditions in mock control cells (Fig. 3). However, no inhibitory effects of papaverine on migration were observed in dnRAGE-expressing HT1080 cells (Fig. 3), which indicated a selective inhibitory action of papaverine against RAGE. Furthermore, papaverine treatment significantly and dose-dependently inhibited HT1080 cell invasion in the Matrigel assay ( $\mathrm{P}<0.01$; Fig. 4). A statistically significant inhibitory effect of papaverine treatment was also identified between treated and non-treated dnRAGE-expressing HT1080 cells $(\mathrm{P}<0.01)$. The results of the present study demonstrated that papaverine may inhibit RAGE-dependent and RAGE-independent malignant phenotypes of cancer cells; the latter may include an antitumor effect of papaverine via an elevation of intracellular cyclic AMP by phosphodiesterase inhibition (8).

\section{Discussion}

RAGE is a multi-ligand, pattern recognition receptor that has been implicated in the growth, progression and metastasis of 
A Papaverine $(\mu \mathrm{M})$
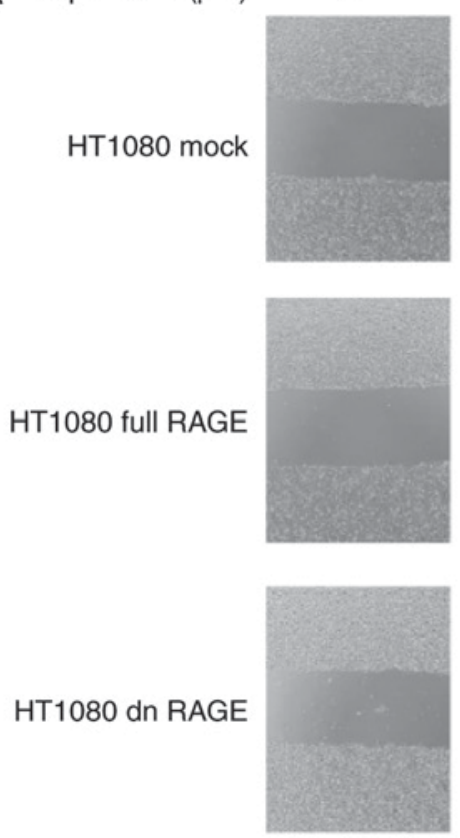

\section{B}

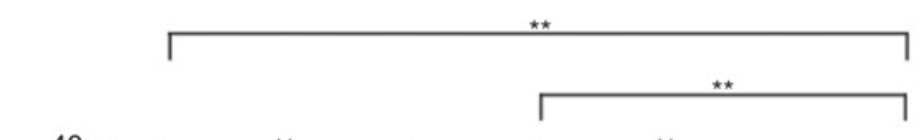

10
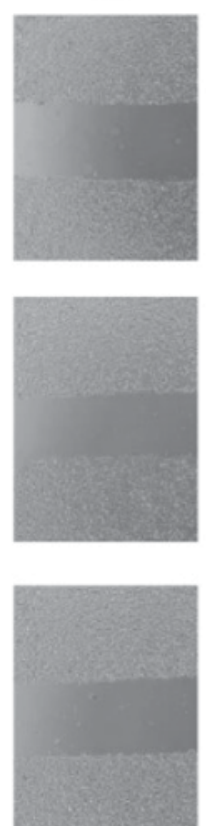

$\mathrm{Oh}$
20
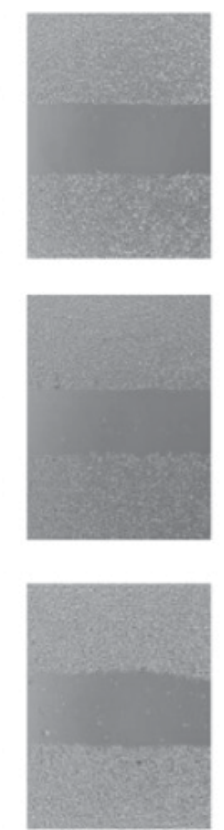

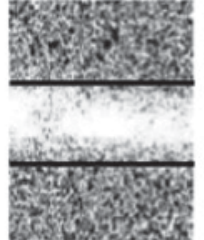

10
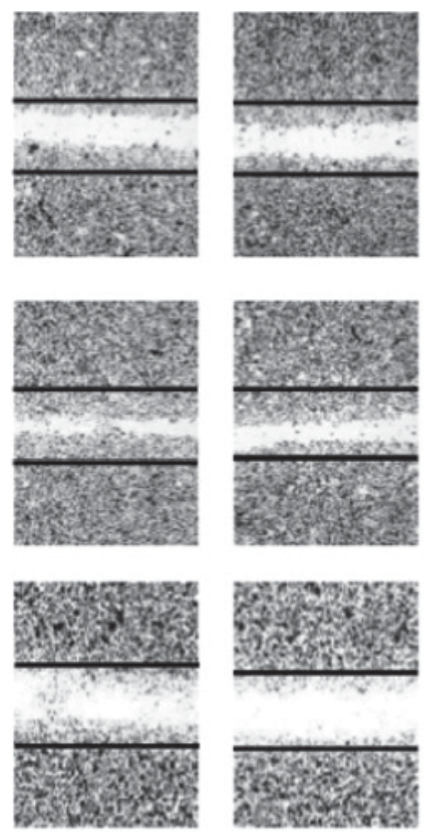

$20 \mathrm{~h}$

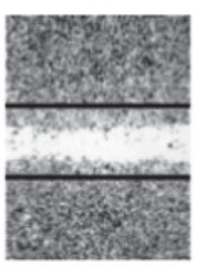

20
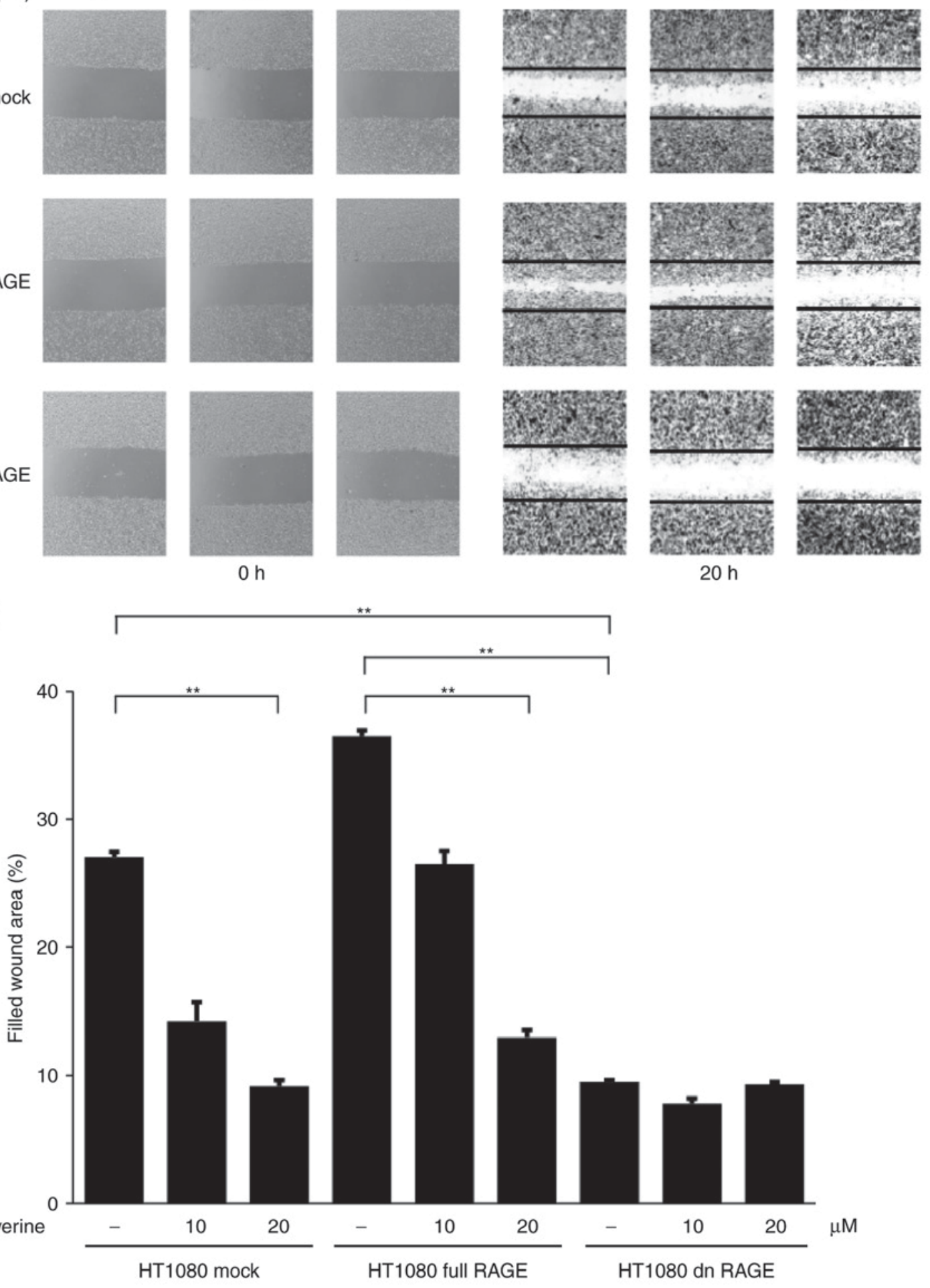

Figure 3. Papaverine inhibits RAGE-induced migration of HT1080 fibrosarcoma cells. (A) Scratch wound assay was performed using HT1080 RAGE, HT1080 dnRAGE and HT1080 mock fibrosarcoma cells in $0.1 \%$ serum medium. (B) The filled wound area was measured. The black line represents the wound edge. -, non-treated control; 10, $10 \mu \mathrm{M}$ papaverine; 20, $20 \mu \mathrm{M}$ papaverine. Values represent the mean \pm standard error of the mean $(\mathrm{n}=3)$. ${ }^{* *} \mathrm{P}<0.01$ between the two groups. RAGE, receptor for advanced glycation end-products; dn, dominant-negative.

multiple types of human cancer $(23,24)$. RAGE ligands include S100/calgranulins (S100A4, S100A6, S100A7, S100A8/9, S100A14, S100B and S100P) (2,25-29) and HMGB-1 protein, which have been demonstrated to be upregulated in glioma, melanoma, bladder, liver, pancreatic, prostate, colorectal, gastric and lung cancer (30-34). Ligand-RAGE signaling pathways enhance the properties associated with malignant tumor phenotypes (10,22,35-37), including by activating members of the small GTPase family (Cdc42 and Rac1), members of the mitogen-activated protein kinase family (extracellular signal-regulated kinase, p38 and stress-activated protein kinases/c-Jun amino-terminal kinases), NF- $\kappa \mathrm{B}$ and the formin homology 1 domain (10,22,35-37). Therefore, blocking RAGE and ligand-RAGE signaling could represent a potential strategy 
A

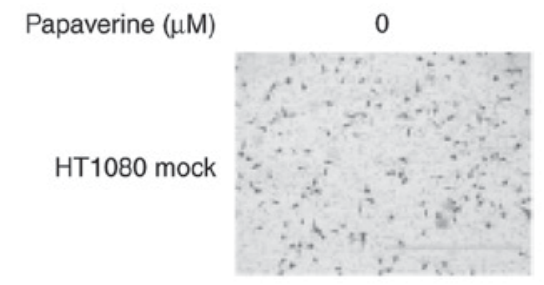

HT1080 full RAGE

HT1080 dn RAGE
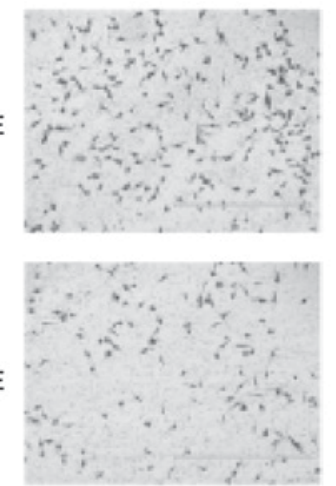

10
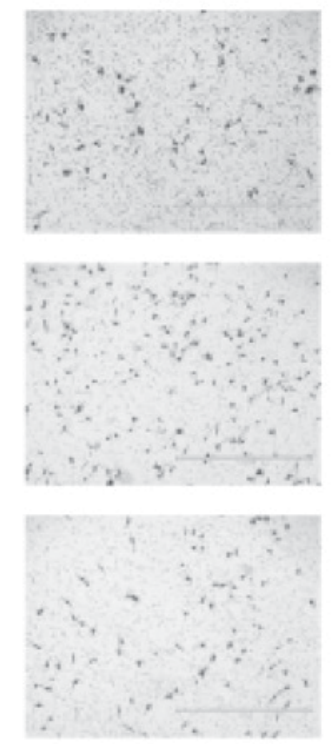

20
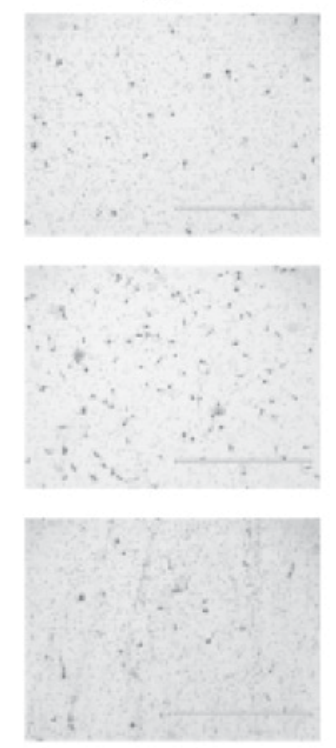

B
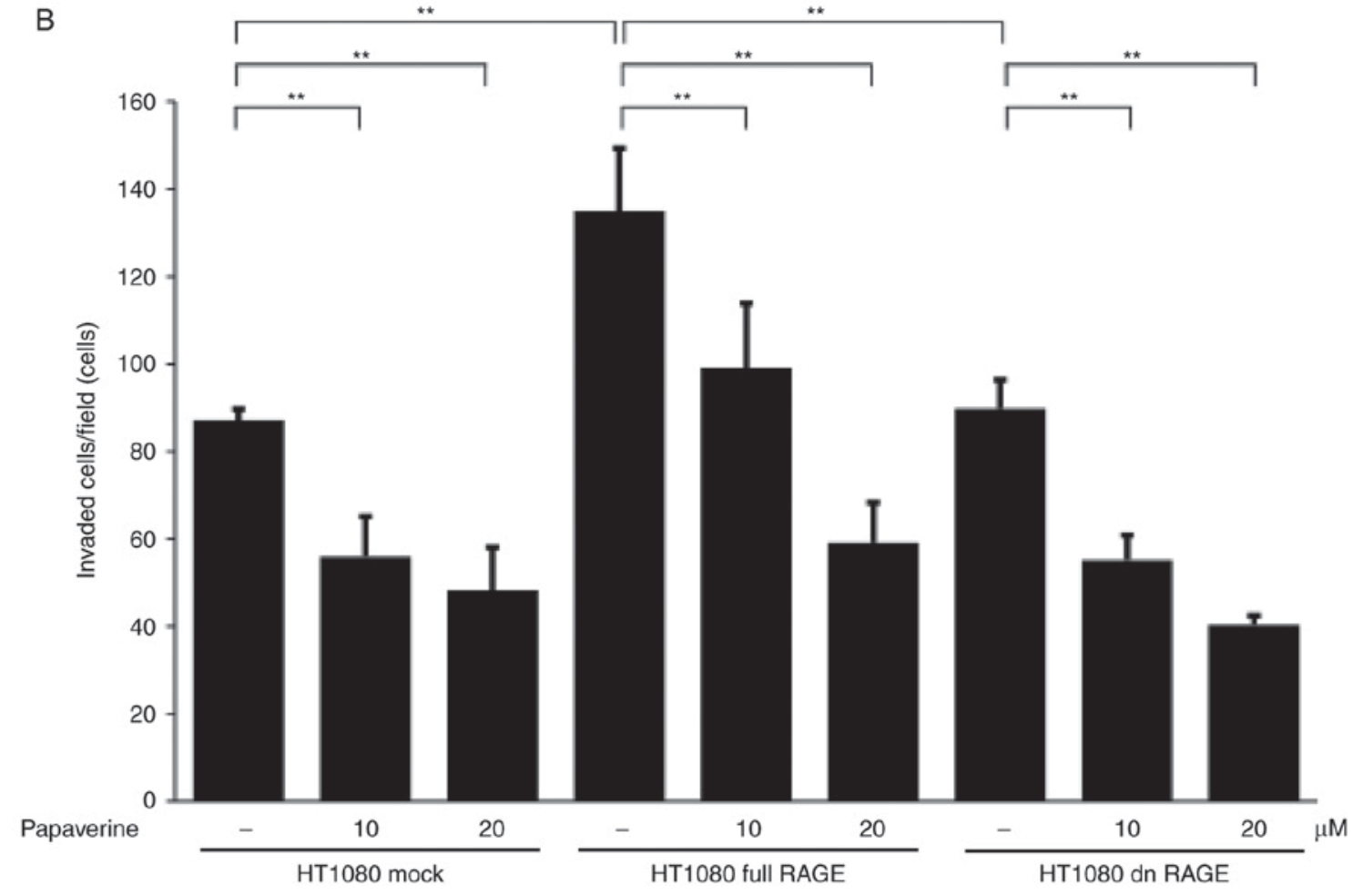

Figure 4. Papaverine inhibits RAGE-induced invasion of HT1080 fibrosarcoma cells. (A) Matrigel cell invasion assay was performed using HT1080 RAGE, HT1080 dnRAGE and HT1080 mock fibrosarcoma cells. Scale bar, $1 \mathrm{~mm}$. (B) The number of migrating cells was determined. -, non-treated control; 10, $10 \mu \mathrm{M}$ papaverine; $20,20 \mu \mathrm{M}$ papaverine. Values represent the mean \pm standard error of the mean $(\mathrm{n}=3) .{ }^{* * *} \mathrm{P}<0.01$. RAGE, receptor for advanced glycation end-products; dn, dominant-negative.

for treating certain types of cancer. Previous experimental studies have revealed that inhibiting RAGE suppressed tumor growth, invasion and angiogenesis in multiple types of cancer $(10,16,38)$. The therapeutic efficacy of blocking RAGE from interacting with HMGB-1 was initially demonstrated in glioma cells, in which this blockade inhibited tumor growth and invasion (16). Subsequently, strategies and components of RAGE inhibition have been reported in oncology and other fields, including neurology $(39,40)$. For example, RAGE-neutralizing antibodies and sRAGE decreased the emergence of lung metastasis following intracardiac injection of Lewis lung carcinoma cells $(39,40)$. In addition, endogenous secretory receptor for advanced glycation end products, another soluble decoy form of RAGE, was demonstrated to inhibit $A \beta-42$ uptake into mouse brain; therefore, it may be effective in AD (41). Hong et al (42) evaluated the effects of the RAGE-specific inhibitor FPS-ZM1 on $A \beta$ metabolism, AGE-induced inflammation and oxidative stress in rat hippocampus. In addition, blocking RAGE signaling in tumor-associated macrophages has been proposed as a potential anticancer strategy; the macrophages form the tumor 
microenvironment, which could drive tumor angiogenesis (30). FPS-ZM1 directly inhibited primary tumor growth; in addition, it blocked RAGE signaling in tumor-associated macrophages, inhibited tumor angiogenesis and inflammatory cell recruitment and inhibited metastasis to the lungs and liver (16). Another RAGE-binding peptide, RP-1, was demonstrated to inhibit $\mathrm{A} \beta$-induced cellular stress in human neuroblastoma cells in vitro (43). Furthermore, Han et al (44) reported that 4,6-bisphenyl-2-(3-alkoxyanilino) pyrimidine inhibited the binding of $A \beta$ to RAGE.

The present study identified papaverine as a RAGE inhibitor using the drug design system COSMOS, an example of drug repositioning, the application of well-known existing drugs and compounds for novel indications. As a structure from which researchers could develop novel drugs, papaverine could represent a potential precursor to a therapeutic RAGE inhibitor. RAGE has been implicated in multiple pathogenic processes, in cancer and numerous other diseases, including diabetes, atherosclerosis, inflammatory and neurodegenerative diseases $(7-9,45)$. Therefore, papaverine and its derivatives could be useful in preventing and treating multiple RAGE-associated diseases. To clarify our understanding of RAGE inhibition by papaverine, in vivo animal models should be used in future studies.

To conclude, the results of the present study suggested papaverine could inhibit RAGE and provided novel insights into the field of RAGE biology.

\section{Acknowledgements}

The authors would like to thank Ms. Yuko Niimura (Kanazawa University) for her technical assistance. The Government of Egypt funded the visit of Dr El-Far to Japan as a post-doctoral fellow for 6 months in 2015. The present study was supported by the Japan Society for the Promotion of Science (grant no. 26450152).

\section{References}

1. Schmidt AM, Vianna M, Gerlach M, Brett J, Ryan J, Kao J, Esposito C, Hegarty H, Hurley W, Clauss M, et al: Isolation and characterization of two binding proteins for advanced glycosylation end products from bovine lung which are present on the endothelial cell surface. J Biol Chem 267: 14987-14997, 1992.

2. Hofmann MA, Drury S, Fu C, Qu W, Taguchi A, Lu Y, Avila C, Kambham N, Bierhaus A, Nawroth P, et al: RAGE mediates a novel proinflammatory axis: A central cell surface receptor for S100/calgranulin polypeptides. Cell 97: 889-901, 1999.

3. Yamamoto Y, Harashima A, Saito H, Tsuneyama K, Munesue S, Motoyoshi S, Han D, Watanabe T, Asano M, Takasawa S, et al: Septic shock is associated with receptor for advanced glycation endproducts (RAGE) ligation of LPS. J Immunol 186: 3248-3257, 2011.

4. He M, Kubo H, Morimoto K, Fujino N, Suzuki T, Takahasi T, Yamada M, Yamaya M, Maekawa T, Yamamoto Y and Yamamoto H: Receptor for advanced glycation end products binds to phosphatidylserine and assists in the clearance of apoptotic cells. EMBO Rep 12: 358-364, 2011.

5. Yan SD, Chen X, Fu J, Chen M, Zhu H, Roher A, Slattery T, Zhao L, Nagashima M, Morser J, et al: RAGE and amyloid-beta peptide neurotoxicity in Alzheimer's disease. Nature 382: 685-691, 1996

6. Hori O, Brett J, Slattery T, Cao R, Zhang J, Chen J, Nagashima M, Lundh ER, Vijay S, Nitecki D, et al: The receptor for advanced glycation end products (RAGE) is a cellular binding site for amphoterin: Mediation of neurite outgrowth and co-expression of rage and amphoterin in the developing nervous system. J Biol Chem 270: 25752-25761, 1995.
7. Yamamoto Y, Kato I, Doi T, Yonekura H, Ohashi S, Takeuchi M, Watanabe T, Yamagishi S, Sakurai S, Takasawa S, et al: Development and prevention of advanced diabetic nephropathy in RAGE-overexpressing mice. J Clin Invest 108: 261-268, 2001.

8. Schmidt AM, Yan SD, Yan SF and Stern DM: The multiligand receptor RAGE as a progression factor amplifying immune and inflammatory responses. J Clin Invest 108: 949-955, 2001.

9. Sims GP, Rowe DC, Rietdijk ST, Herbst R and Coyle AJ: HMGB1 and RAGE in inflammation and cancer. Annu Rev Immunol 28 367-388, 2010.

10. Takeuchi A, Yamamoto Y,Munesue S, Harashima A, Watanabe T, Yonekura H, Yamamoto $\mathrm{H}$ and Tsuchiya H: Low molecular weight heparin suppresses receptor for advanced glycation end products-mediated expression of malignant phenotype in human fibrosarcoma cells. Cancer Sci 104: 740-749, 2013.

11. Kuniyasu H, Oue N, Wakikawa A, Shigeishi H, Matsutani N, Kuraoka K, Ito R, Yokozaki H and Yasui W: Expression of receptors for advanced glycation end-products (RAGE) is closely associated with the invasive and metastatic activity of gastric cancer. J Pathol 196: 163-170, 2002.

12. Fuentes MK, Nigavekar SS, Arumugam T, Logsdon CD, Schmidt AM, Park JC and Huang EH: RAGE activation by S100P in colon cancer stimulates growth, migration, and cell signaling pathways. Dis Colon Rectum 50: 1230-1240, 2007.

13. Onyeagucha BC, Mercado-Pimentel ME, Hutchison J, Flemington EK and Nelson MA: S100P/RAGE signaling regulates microRNA-155 expression via AP-1 activation in colon cancer. Exp Cell Res 319: 2081-2090, 2013.

14. Mercado-Pimentel ME, Onyeagucha BC, Li Q, Pimentel AC, Jandova $J$ and Nelson MA: The S100P/RAGE signaling pathway regulates expression of microRNA-21 in colon cancer cells. FEBS Lett 589: 2388-2393, 2015.

15. Ishiguro H, Nakaigawa N, Miyoshi Y, Fujinami K, Kubota Y and Uemura $\mathrm{H}$ : Receptor for advanced glycation end products (RAGE) and its ligand, amphoterin are overexpressed and associated with prostate cancer development. Prostate 64: 92-100, 2005.

16. Kwak T, Drews-Elger K, Ergonul A, Miller PC, Braley A, Hwang GH, Zhao D, Besser A, Yamamoto Y, Yamamoto H, et al: Targeting of RAGE-ligand signaling impairs breast cancer cell invasion and metastasis. Oncogene 36: 1559-1572, 2017.

17. Zhang Q, Jin Y, Zhao CF, Wang WJ and Liu GY: Receptor for advanced glycation end-products (RAGE) is overexpressed in human osteosarcoma and promotes the proliferation of osteosarcoma U-2OS cells in vitro. Genet Mol Res 15, 2016.

18. Sakai J, Yoshimori A, Nose Y, Mizoroki A, Okita N, Takasawa R and Tanuma S: Structure-based discovery of a novel non-peptidic small molecular inhibitor of caspase-3. Bioorg Med Chem 16: 4854-4859, 2008.

19. Kukovetz WR and Pöch G: Inhibition of cyclic-3', 5'-nucleotide-phosphodiesterase as a possible mode of action of papaverine and similarly acting drugs. Naunyn Schmiedebergs Arch Pharmakol 267: 189-194, 1970.

20. Iguchi M, Nakajima T, Hisada T, Sugimoto T and Kurachi Y: On the mechanism of papaverine inhibition of the voltage-dependent $\mathrm{Ca}^{++}$current in isolated smooth muscle cells from the guinea pig trachea. J Pharmacol Exp Ther 263: 194-200, 1992.

21. Myint KM, Yamamoto Y,Doi T, Kato I,Harashima A, Yonekura H, Watanabe T, Shinohara H, Takeuchi M, Tsuneyama K, et al: RAGE control of diabetic nephropathy in a mouse model: Effects of RAGE gene disruption and administration of low-molecular weight heparin. Diabetes 55: 2510-2522, 2006.

22. Huttunen HJ, Fages $\mathrm{C}$ and Rauvala $\mathrm{H}$ : Receptor for advanced glycation end products (RAGE)-mediated neurite outgrowth and activation of $\mathrm{NF}-\kappa \mathrm{B}$ require the cytoplasmic domain of the receptor but different down signaling pathways. J Biol Chem 274: 19919-19924, 1999.

23. Huttunen HJ, Fages C, Kuja-Panula J, Ridley AJ and Rauvala H: Receptor for advanced glycation end products-binding $\mathrm{COOH}$-terminal motif of amphoterin inhibits invasive migration and metastasis. Cancer Res 62: 4805-4811, 2002.

24. Wajsman Z, Williams P and Murphy GP: A study of the effect of papaverine in neuroblastoma using the experimental C1300 murine system. Oncology 35: 1-4, 1978.

25. Wolf S, Haase-Kohn C, Lenk J, Hoppmann S, Bergmann R, Steinbach J and Pietzsch J: Expression, purification and fluorine-18 radiolabeling of recombinant S100A4: A potential probe for molecular imaging of receptor for advanced glycation endproducts in vivo? Amino Acids 41: 809-820, 2011. 
26. Leclerc E, Fritz G, Weibel M, Heizmann CW and Galichet A S100B and S100A6 differentially modulate cell survival by interacting with distinct RAGE (receptor for advanced glycation end products) immunoglobulin domains. J Biol Chem 282: 31317-31331, 2007.

27. Wolf R, Howard OM, Dong HF, Voscopoulos C, Boeshans K, Winston J, Divi R, Gunsior M, Goldsmith P, Ahvazi B, et al: Chemotactic activity of S100A7 (Psoriasin) is mediated by the receptor for advanced glycation end products and potentiates inflammation with highly homologous but functionally distinct S100A15. J Immunol 181: 1499-1506, 2008.

28. Jin Q, Chen H, Luo A, Ding F and Liu Z: S100A14 stimulates cell proliferation and induces cell apoptosis at different concentrations via receptor for advanced glycation end products (RAGE). PLoS One 6: e19375, 2011.

29. Padilla L, Dakhel S and Hernández JL: S100 to receptor for advanced glycation end-products binding assay: Looking for inhibitors. Biochem Biophys Res Commun 446: 404-409, 2014.

30. Chen X, Zhang L, Zhang IY, Liang J, Wang H, Ouyang M, Wu S, da Fonseca AC, Weng L, Yamamoto Y, et al: RAGE expression in tumor-associated macrophages promotes angiogenesis in glioma. Cancer Res 74: 7285-7297, 2014.

31. Khorramdelazad H, Bagheri V, Hassanshahi G, Karami H, Moogooei M, Zeinali M and Abedinzadeh M: S100A12 and RAGE expression in human bladder transitional cell carcinoma: A role for the ligand/RAGE axis in tumor progression? Asian Pac J Cancer Prev 16: 2725-2729, 2015.

32. Meghnani V, Wagh A, Indurthi VS, Koladia M, Vetter SW Law B and Leclerc E: The receptor for advanced glycation end products influences the expression of its S100 protein ligands in melanoma tumors. Int J Biochem Cell Biol 57: 54-62, 2014.

33. Kostova N, Zlateva S, Ugrinova I and Pasheva E: The expression of HMGB1 protein and its receptor RAGE in human malignant tumors. Mol Cell Biochem 337: 251-258, 2010.

34. Sparvero LJ, Asafu-Adjei D, Kang R, Tang D, Amin N, Im J, Rutledge R, Lin B, Amoscato AA, Zeh HJ and Lotze MT: RAGE (Receptor for Advanced Glycation Endproducts), RAGE ligands, and their role in cancer and inflammation. J Transl Med 7: 17, 2009.

35. Wu R, Duan L, Cui F, Cao J, Xiang Y, Tang Y and Zhou L: S100A9 promotes human hepatocellular carcinoma cell growth and invasion through RAGE-mediated ERK1/2 and p38 MAPK pathways. Exp Cell Res 334: 228-238, 2015.
36. Iotzova-Weiss G, Dziunycz PJ, Freiberger SN, Läuchli S, Hafner J, Vogl T, French LE and Hofbauer GF: S100A8/A9 stimulates keratinocyte proliferation in the development of squamous cell carcinoma of the skin via the receptor for advanced glycation-end products. PLoS One 10: e120971, 2015.

37. Hudson BI, Kalea AZ, Del Mar Arriero M, Harja E, Boulanger E, D'Agati V and Schmidt AM: Interaction of the RAGE cytoplasmic domain with diaphanous-1 is required for ligand-stimulated cellular migration through activation of Rac1 and Cdc42. J Biol Chem 283: 34457-34468, 2008.

38. Kalea AZ, See F, Harja E, Arriero M, Schmidt AM and Hudson BI: Alternatively spliced RAGEv1 inhibits tumorigenesis through suppression of JNK signaling. Cancer Res 70: 5628-5638, 2010

39. Taguchi A, Blood DC, del Toro G, Canet A, Lee DC, Qu W, Tanji N, Lu Y, Lalla E, Fu C, et al: Blockade of RAGE-amphoterin signalling suppresses tumour grow th and metastases. Nature 405: 354-360, 2000

40. Mizumoto S, Takahashi J and Sugahara K: Receptor for advanced glycation end products (RAGE) functions as receptor for specific sulfated glycosaminoglycans, and anti-RAGE antibody or sulfated glycosaminoglycans delivered in vivo inhibit pulmonary metastasis of tumor cells. J Biol Chem 287: 18985-18994, 2012.

41. Sugihara T, Munesue S, Yamamoto Y, Sakurai S, Akhter N, Kitamura Y, Shiba K, Watanabe T, Yonekura H, Hayashi Y, et al: Endogenous secretory receptor for advanced glycation end-products inhibits amyloid- $\beta 1-42$ uptake into mouse brain. J Alzheimers Dis 28: 709-720, 2012.

42. Hong Y, Shen C, Yin Q, Sun M, Ma Y and Liu X: Effects of RAGE-specific inhibitor FPS-ZM1 on amyloid- $\beta$ metabolism and AGEs-induced inflammation and oxidative stress in rat hippocampus. Neurochem Res 41: 1192-1199, 2016.

43. Cai C, Dai X, Zhu Y, Lian M, Xiao F, Dong F, Zhang Q, Huang Y and Zheng Q: A specific RAGE-binding peptide biopanning from phage display random peptide library that ameliorates symptoms in amyloid $\beta$ peptide-mediated neuronal disorder. Appl Microbiol Biotechnol 100: 825-835, 2016.

44. Han YT, Kim K, Son D, An H, Kim H, Lee J, Park HJ, Lee J and Suh YG: Fine tuning of 4,6-bisphenyl-2-(3-alkoxyanilino) pyrimidine focusing on the activity-sensitive aminoalkoxy moiety for a therapeutically useful inhibitor of receptor for advanced glycation end products (RAGE). Bioorg Med Chem 23: 579-587, 2014.

45. Kalea AZ, Schmidt AM and Hudson BI: RAGE: A novel biological and genetic marker for vascular disease. Clin Sci (Lond) 116: 621-637, 2009. 